\title{
ESTUDO DA RELAÇÃO ENTRE CONDIÇÕES DE POLPAÇÃO E PROPRIEDADES FÍSICO-MECÂNICAS DO PAPEL
}

\author{
Danila Morais de Carvalho², Marcelo Rodrigues da Silva ${ }^{3}$ e Jorge Luiz Colodette ${ }^{4}$
}

\begin{abstract}
RESUMO - O objetivo deste estudo foi avaliar a influência da condição de polpação nas propriedades físicomecânicas do papel branqueado de eucalipto. Para este estudo, foram utilizados cavacos de um híbrido clonal de eucalipto (Eucalyptus grandis x Eucalyptus urophylla) de 7 anos de idade. As polpas foram produzidas por duas condições distintas de polpação Lo-Solids ${ }^{\mathrm{TM}}$, sendo elas: Condição PI - álcali efetivo de 16,5\%, sulfidez de $30 \%$ e temperatura de cozimento de $155^{\circ} \mathrm{C}$; e Condição PII - álcali efetivo de $17,5 \%$, sulfidez de $32 \%$ e temperatura de cozimento de $147^{\circ} \mathrm{C}$. Ambos os cozimentos foram realizados buscando-se número kappa de $18,0 \pm 0,5$. Os branqueamentos foram realizados pela sequência de branqueamento OA(Ze)DP, buscando-se a alvura de 90,0 $\pm 1,0 \%$ ISO. Os refinos foram realizados a 0,750, 1.500 e 3.000 níveis de revoluções e as correlações, feitas utilizando o índice de tração como variável independente da curva de refino. As propriedades físico-mecânicas do papel foram influenciadas pela condição de polpação, com aumento da drenabilidade, densidade aparente, índice TEA, alongamento e índice de rasgo para a polpa PI, considerando-se um mesmo índice de tração. A polpa PII, entretanto, atingiu o mesmo índice de tração da polpa PI com menor nível de refino e, consequentemente, menor gasto de energia. A condição de polpação PII foi mais adequada para a produção de papel por preservar mais a integridade das fibras, alcançando um mesmo índice de tração com um menor nível de refino.
\end{abstract}

Palavras-chave: Refino; Índice de tração; Polpa de eucalipto.

\section{STUDY OF THE RELATIONSHIP BETWEEN PULPING CONDITIONS AND THE PHYSICAL-MECHANICAL PROPERTIES OF PAPER}

\begin{abstract}
The aim of this study was to evaluate the influence of the pulping condition on the physicalmechanical properties of the eucalyptus bleached paper. Wood chips from a seven-year-old clonal hybrid of eucalyptus were used (Eucalyptus grandis $x$ Eucalyptus urophylla). The pulps were obtained from two distinct Lo-Solids ${ }^{T M}$ pulping conditions, namely: Condition PI - $16.5 \%$ effective alkali, $30 \%$ sulfidity, and $155^{\circ} \mathrm{C}$ cooking temperature; and Condition PII - $17.5 \%$ effective alkali, $32 \%$ sulfidity, and $147^{\circ} \mathrm{C}$ cooking temperature. Both conditions were performed to kappa number $18.0 \pm 0.5$. The bleaching were performed following the bleaching sequences $O A(Z e) D P$ to achieve $90 \pm 1 \%$ ISO brightness. The refinings were made at 0, 750, 1,500 and 3,000 revolution levels and the correlations were made based on the tensile index as independent variable of the refining curves. The physical-mechanical properties of the paper was influenced by the pulping conditions, with increasing of drainability, apparent density, TEA index, stretching and tear index to the PI pulp, considering the same tensile index. The PII pulp, however, achieved the same tensile index of PI pulp with lower refining level, thus, with lower energy waste. The pulping condition PII was most suitable for paper production for preserving more the integrity of the fibers, achieving the same tensile index with a lower refining level.
\end{abstract}

Keywords: Refining; Tensile index; Eucalyptus pulp.

\footnotetext{
${ }^{1}$ Recebido em 23.05.2013 aceito para publicação em 07.04.2015

${ }^{2}$ Universidade Federal de Viçosa, Programa de Pós-Graduação em Ciência Florestal, Viçosa, Minas Gerais, Brasil. E-mail: $<$ carvalho.danila@gmail.com>.

${ }^{3}$ Empresa Fibria, Jacareí, São Paulo, Brasil. E-mail: <marcelo.silva@fibria.com.br>.

${ }^{4}$ Universidade Federal de Viçosa, Departamento de Engenharia Florestal, Viçosa, Minas Gerais, Brasil. E-mail: <colodett@ufv.br> .
}

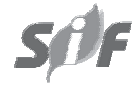

Revista Árvore, Viçosa-MG, v.39, n.3, p.575-584, 2015

http://dx.doi.org/10.1590/0100-67622015000300019 


\section{INTRODUÇÃO}

A utilização do gênero Eucalyptus no país tem-se destacado ao longo dos anos em decorrência não somente da grande variedade de espécies botânicas cultivadas e melhoradas, como também da boa adaptabilidade do gênero às condições edafoclimáticas brasileiras. Aliado a isso, práticas sustentáveis de manejo e pesquisas no campo florestal têm cada vez mais favorecido o desenvolvimento das tecnologias silviculturais dos plantios, o que tem contribuído para o sucesso dos programas de melhoramento genético dessas espécies, bem como para a agregação de valor ao produto final industrializado produzido a partir dessas madeiras (OLIVEIRA et al., 2012).

Entre os ramos industriais de base florestal que utilizam o eucalipto, a produção de polpa celulósica para papel merece destaque, sendo as principais etapas presentes na produção a polpação química, o branqueamento e o refino.

A primeira etapa de transformação química da madeira para a produção de papel é a polpação, que no Brasil é, principalmente, realizada pelo processo Kraft (SILVA et al., 2004; QUEIROZ et al., 2004; GOMIDE et al., 2005; VENTORIM et al., 2009). O processo de polpação objetiva separar as fibras de celulose por meio da retirada da lignina. Entretanto, durante essa etapa, outras reações químicas ocorrem transformando os constituintes da madeira. Conforme Zanuncio e Colodette (2011), a madeira de eucalipto apresenta considerável quantidade de ácidos urônicos. Tais ácidos encontram na polpação Kraft condições reacionais adequadas à sua conversão a ácidos hexenurônicos, compostos que prejudicam o processo de branqueamento (etapa seguinte do processo de produção de polpa celulósica), por consumir parte dos reagentes utilizados e, ainda, comprometer a qualidade da polpa branqueada produzida (JIANG et al., 2000; SIXTA; RUTKOWSKA, 2007).

Variáveis da polpação como tempo, carga alcalina e sulfidez determinam a dinâmica de formação dos ácidos hexenurônicos (DANIEL et al., 2003). Durante a polpação, ácidos urônicos reagem com o licor de cozimento formando ácidos hexenurônicos. Em determinado ponto da polpação, os ácidos hexenurônicos começam a ser degradados pelo próprio licor de cozimento. A carga alcalina $\left[\mathrm{OH}^{-}\right]$atua tanto na formação quanto na degradação dos ácidos hexenurônicos, com efeito positivo do aumento da carga alcalina na degradação dos ácidos hexenurônicos formados (GUSTAVSSON et al., 1999). A sulfidez não influencia diretamente na cinética da formação/degradação desses ácidos, mas atua indiretamente, facilitando a acessibilidade do licor de cozimento à lignina, devido à sua alta seletividade durante o processo de deslignificação. Por consequência, a degradação dos ácidos hexenurônicos pelo licor de cozimento é favorecida (SIXTA; RUTKOWSKA, 2007). As condições de polpação que favorecem a formação e degradação dos ácidos hexenurônicos, entretanto, dependem da composição química da madeira utilizada. O teor de ácidos hexenurônicos da polpa pode ainda afetar sua branqueabilidade (VENTORIM et al., 2009), o que indica que a qualidade da celulose branqueada produzida é função de diversos fatores e as características tecnológicas adotadas durante o processo de polpação e branqueamento podem favorecer ou comprometer certas características do produto final.

Por fim, com o intuito de desenvolver resistência físico-mecânica no papel, é realizado o refino da polpa celulósica. Podem ser associados ao refino diversos efeitos para as fibras, sendo eles: fibrilação interna - promovendo aumento da flexibilidade das fibras; fibrilação externa - com formação de filamentos superficiais que aumentam o entrelaçamento entre as fibras e, consequentemente, incrementam a resistência do papel (MANFREDI et al., 2012); encurtamento de fibras - causado pelo seu corte nas lâminas do refinador; e formação de finos - causada pelo destacamento total de partículas das paredes primária e secundária das fibras, além de cortes longitudinais. Esses dois últimos efeitos são altamente indesejáveis.

O objetivo foi avaliar a influência das condições de polpação (tempo, temperatura, carga alcalina e sufidez) nas propriedades físico-mecânicas do papel.

\section{MATERIAL E MÉTODOS}

\subsection{Material}

Para a realização deste estudo, foram utilizados cavacos de madeira de eucalipto de um híbrido clonal (Eucalyptus grandis x Eucalyptus urophylla) de aproximadamente 7 anos de idade e densidade básica de $542 \mathrm{~kg} / \mathrm{m}^{3}$ e com a seguinte composição química (base matéria-prima seca com extrativos): $0,20 \% \mathrm{de}$ cinzas; $0,013 \%$ de materiais insolúveis em $\mathrm{HCl} ; 3,4 \%$ de extrativos totais; $3,59 \%$ de lignina solúvel; $24,92 \%$

Revista Árvore, Viçosa-MG, v.39, n.3, p.575-584, 2015 
de lignina insolúvel; $28,51 \%$ de lignina total; e 67,89\% de holocelulose.

\section{2. Produção de polpa Kraft}

Os cavacos foram classificados de acordo com a metodologia SCAN-CM 40:94 (SCAN, 1994). Os cozimentos foram realizados em triplicata em digestor MK, acoplados a vasos de armazenamento de licor, buscando-se o número kappa de 18,0 $\pm 0,5$. As polpas foram produzidas segundo a tecnologia Lo-Solids ${ }^{\mathrm{TM}}$, conforme procedimento do Centro de Tecnologia e Pesquisa (Fibria-Jacareí), efetuando-se, além da dosagem de alimentação, mais duas dosagens de licor branco durante o cozimento. Dessa forma, o cozimento foi dividido em fase de impregnação (alimentação), fase de cozimento I (transferência) e fase de cozimento II (extração).

Antes do processo de polpação propriamente dito, foi feita a etapa de vaporização nos cavacos. A execução desta etapa consistiu em injetar vapor a $100^{\circ} \mathrm{C}$ nos cavacos já pesados ( $1.400 \mathrm{~g}$ secos $)$ por $15 \mathrm{~min}$. Após a vaporização, os cavacos foram pesados e a quantidade de vapor de água neles retida foi descontada do volume de água a ser adicionado para suprir a relação licor/ madeira de 3,5/1 (v/m), que foi utilizada para a realização dos cozimentos.

O licor de cozimento foi preparado em laboratório a partir de hidróxido de sódio fornecido pelo processo fabril e sulfeto de sódio sólido, com padronização do licor preparado antes de cada novo cozimento. Foram utilizadas duas condições de cozimento, sendo elas: condição PI (álcali efetivo de 16,5\%, sulfidez de 30,0\%, temperatura de cozimento de $155^{\circ} \mathrm{C}$, tempo até a temperatura de 141 min e tempo à temperatura de 94 min) e condição PII (álcali efetivo de $17,5 \%$, sulfidez de $32,0 \%$, temperatura de cozimento de $147^{\circ} \mathrm{C}$, tempo até a temperatura de 126 min e tempo à temperatura de $146 \mathrm{~min}$ ). Em ambas as condições, o tempo foi a variável alterada, a fim de obter o número kappa de interesse, resultando em cozimentos com fator $\mathrm{H}$ de 525 e 396, nas condições PI e PII, respectivamente. A distribuição da carga alcalina na alimentação, transferência e extração foi, respectivamente, de 7,6\%, 1,8\% e 1,7\% para a condição PI e de $7,9 \%, 4,9 \%$ e $4,7 \%$ para a condição PII.

Após os cozimentos, as polpas foram lavadas e depuradas em depurador laboratorial da marca Voith, dotado de placa com fendas de 0,2 $\mathrm{mm}$. Os feixes de fibras e fragmentos de cavacos mal cozidos retidos nas fendas foram quantificados para a determinação do teor de rejeitos do cozimento.

O processo de cozimento foi avaliado quanto ao rendimento depurado. As polpas depuradas foram avaliadas quanto ao número kappa (TAPPI T236 om-06), viscosidade intrínseca (TAPPI T230 om-08), alvura (TAPPI T452 om-08), conteúdo de ácidos hexenurônicos (Método interno Fibria - Jacareí) e índice k/kappa corrigido, metodologia adaptada de diversos autores (LI; GELLERSTEDT, 1997; AL-DAJANI, 2001; ABNT, 2009), conforme descrito em um estudo prévio (CARVALHO et al., 2014). Os resultados foram submetidos ao teste Tukey a 5\% de significância.

\subsection{Produção das polpas branqueadas}

Os branqueamentos das polpas produzidas no cozimento foram realizados em duplicata, seguindo a sequência OA(Ze)DP e buscando obter alvura de 90,0 $\pm 1,0 \%$ ISO. As condições gerais do branqueamento estão apresentadas na Tabela 1. As polpas branqueadas foram investigadas quanto à viscosidade intrínseca (TAPPI T230 om-08), alvura (TAPPI T452 om-08) e branqueabilidade (razão entre a quantidade de reagentes químicos utilizados para obter a mesma alvura final e o número kappa da polpa não branqueada), conforme descrito em um estudo prévio (CARVALHO et al., 2015). $\mathrm{O}$ consumo dos reagentes químicos do branqueamento foi definido após a conversão dos químicos utilizados para o equivalente de oxidação (OXE) a eles associados, de acordo com Grundelius (1993). Os resultados dos parâmetros avaliados foram submetidos ao teste de Tukey a 5\% de significância.

\subsection{Refino e propriedades físico-mecânicas}

Os refinos foram realizados em quatro níveis, sendo eles: 0, 750, 1.500 e 3.000 revoluções, em moinho PFI (TAPPI T248 sp-08). Após o refino, folhas de teste foram formadas de acordo com TAPPI T205 sp-06, com gramatura de $60 \mathrm{~g} / \mathrm{m}^{2}$ (TAPPI T410 om-08). Foram formadas 12 folhas por tratamento, e elas foram acondicionadas em ambiente climatizado com temperatura de $23 \pm 1{ }^{\circ} \mathrm{C}$ e umidade relativa de 50 $\pm 2 \%$. Os testes físico-mecânicos realizados foram: drenabilidade (TAPPI T423 cm-07), densidade aparente (TAPPI T220 sp-06), resistência ao ar (TAPPI T460 om-02), índice TEA (TAPPI T494 om-06), alongamento (TAPPI T494 om-06), índice de tração (TAPPI T494

Revista Árvore, Viçosa-MG, v.39, n.3, p.575-584, 2015 
Tabela 1 - Condições gerais do branqueamento.

Table 1 - General bleaching conditions.

\begin{tabular}{|c|c|c|c|c|c|}
\hline Parâmetros & $\mathrm{O}$ & A & $(\mathrm{Ze})$ & $\mathrm{D}$ & $\mathrm{P}$ \\
\hline Consistência, \% & 10 & 11 & $40 / 11$ & 11 & 11 \\
\hline Temperatura, ${ }^{\circ} \mathrm{C}$ & 100 & 40 & $40 / 65$ & 80 & 90 \\
\hline Tempo de residência, min & 60 & 10 & Variável / 10 & 60 & 120 \\
\hline $\mathrm{pH}$ final & & 2,8 & $-/ 10,5$ & 3,0 & 11,0 \\
\hline Carga $\mathrm{O}_{3}, \mathrm{~kg} / \mathrm{adt}$ & & & $3,0 /-$ & & \\
\hline Carga $\mathrm{O}_{2}, \mathrm{~kg} / \mathrm{adt}$ & 18 & & & & \\
\hline Carga $\mathrm{NaOH}, \mathrm{kg} / \mathrm{adt}$ & 18 & & $-/ \mathrm{pH}^{*}$ & $\mathrm{pH}^{*}$ & $\mathrm{pH}^{*}$ \\
\hline Carga $\mathrm{H}_{2} \mathrm{SO}_{4}, \mathrm{~kg} / \mathrm{adt}$ & & $\mathrm{pH}^{*}$ & & $\mathrm{pH}^{*}$ & \\
\hline Carga $\mathrm{ClO}_{2}, \mathrm{~kg} / \mathrm{adt}$ & & & & 10,00 & \\
\hline Carga $\mathrm{H}_{2} \mathrm{O}_{2}, \mathrm{~kg} / \mathrm{adt}$ & & & & & 9,00 \\
\hline Carga $\mathrm{MgSO}_{4}, \mathrm{~kg} / \mathrm{adt}$ & & & & & 2,00 \\
\hline
\end{tabular}

* Concentração acrescentada dependente do pH requerido para a saída do estágio.

* Concentration added in function of the $\mathrm{pH}$ needed in the end of the stage.

om-06), índice de rasgo (TAPPI T414 om-04), índice de estouro (TAPPI T403 om-02) e comprimento de auto-ruptura (TAPPI T494 om-06).

\section{RESULTADOS}

\section{1. Polpação Kraft}

Foram produzidas polpas seguindo duas condições de polpação, sendo elas: condição PI (álcali efetivo de $16,5 \%$, sulfidez de $30,0 \%$, temperatura de cozimento de $155^{\circ} \mathrm{C}$, tempo até a temperatura de 141 min e tempo à temperatura de $94 \mathrm{~min}$ ) e condição PII (álcali efetivo de $17,5 \%$, sulfidez de $32,0 \%$, temperatura de cozimento de $147^{\circ} \mathrm{C}$, tempo até a temperatura de 126 min e tempo à temperatura de $146 \mathrm{~min}$ ). Ambas as condições foram realizadas ao número kappa de 18,0 $\pm 0,5$. Valores médios de rendimento depurado, viscosidade intrínseca, alvura, conteúdo de ácidos hexenurônicos e índice k/kappa corrigido foram obtidos em polpas originadas das condições de polpação PI e PII (Tabela 2).

\subsection{Polpas branqueadas}

As duas polpas produzidas no processo de polpação Kraft foram branqueadas pela sequência OA(Ze)DP até a alvura de 90,0 $\pm 1 \%$ ISO. Os resultados de consumo de reagentes químicos foram interpolados para a alvura de $89 \%$ ISO, para permitir as comparações entre as polpas. Os diversos reagentes químicos de branqueamentos utilizados nesta sequência foram convertidos a uma mesma base química, tendo sido utilizado o equivalente de oxidação (OXE) a eles relacionado (GRUNDELIUS, 1993). A branqueabilidade foi definida como a razão entre o consumo de químicos utilizados no branqueamento para se atingir uma mesma alvura final (89\% ISO) e o número kappa da polpa marrom. Valores médios de viscosidade intrínseca, alvura e branqueabilidade foram obtidos em polpas branqueadas provenientes das condições de polpação PI e PII (Tabela 2).

\subsection{Refino e propriedades físico-mecânicas}

Após a realização dos branqueamentos, as polpas foram refinadas a $0,750,1.500$ e 3.000 níveis de revoluções e as propriedades físico-mecânicas do papel, determinadas (Tabela 3 ).

\section{DISCUSSÃO}

\subsection{Polpação Kraft}

De acordo com os resultados dos parâmetros avaliados na polpação e na polpa Kraft de eucalipto produzidas, verificou-se que as condições de polpação PI e PII, embora distintas, não influenciaram o rendimento depurado e a alvura das polpas. Viscosidade intrínseca, conteúdo de ácidos hexenurônicos e índice k/kappa corrigido foram influenciados pela condição de polpação.

A geração de ácidos hexenurônicos durante o cozimento kraft foi inevitável, embora existam estudos que avaliam formas de controle da geração desse composto a partir da mais adequada utilização de tempo, temperatura de cozimento, concentração da carga alcalina e sulfidez (GUSTAVSSON et al., 1999; DANIEL et al.; 2003; SIXTA; RUTKOWSKA, 2007). Apesar de desempenhar função de proteção à despolimerização terminal das xilanas 
Tabela 2 - Resultados da polpação e branqueamento. Table 2 - Pulping and bleaching results.

\begin{tabular}{|c|c|c|c|}
\hline Etapas & Parâmetros & PI & PII \\
\hline \multirow[t]{5}{*}{ Polpação } & Rendimento depurado, $\%$ & 54,1 a & 54,1 a \\
\hline & Viscosidade intrínseca, $\mathrm{cm}^{3} / \mathrm{g}$ & 1377 a & $1386 \mathrm{~b}$ \\
\hline & Alvura, \% ISO & 40,8 a & 41,0 a \\
\hline & Ácidos hexenurônicos, $\mu \mathrm{mol} / \mathrm{g}$ & $63,7 \mathrm{a}$ & $60,4 \mathrm{~b}$ \\
\hline & Índice $\mathrm{k} / \mathrm{kappa}$ corrigido, $\mathrm{m}^{2} / \mathrm{kg}$ & 0,49 a & $0,47 \mathrm{~b}$ \\
\hline \multirow[t]{3}{*}{ Branqueamento } & Viscosidade intrínseca, $\mathrm{cm}^{3} / \mathrm{g}$ & 744 a & $926 \mathrm{~b}$ \\
\hline & Alvura, \% ISO & 89,5 a & 89,3 a \\
\hline & Branqueabilidade, OXE/adt/ $\Delta$ kappa & 89,3 a & $88,6 \mathrm{~b}$ \\
\hline
\end{tabular}

Médias seguidas de mesma letra por linha não diferem a $5 \%$ de probabilidade pelo teste Tukey.

Means followed by the same letter per row do not differ at $5 \%$ of probability by the Tukey Test.

Tabela 3 - Resultados das propriedades físico-mecânicas do papel.

Table 3 - Results of the physical-mechanical properties of paper.

\begin{tabular}{lcccccccc}
\hline \multicolumn{1}{c}{ Propriedades } & \multicolumn{4}{c}{ Polpa PI } & \multicolumn{4}{c}{ Polpa PII } \\
\hline Níveis de revoluções & 0 & 750 & 1.500 & 3.000 & 0 & 750 & 1.500 & 3.000 \\
Drenabilidade, ${ }^{\circ} \mathrm{SR}$ & 17 & 21 & 29 & 51 & 16 & 23 & 33 & 65 \\
Densidade aparente, $\mathrm{kg} / \mathrm{m}^{3}$ & 502 & 595 & 670 & 753 & 524 & 605 & 675 & 766 \\
Resistência ao ar, $\mathrm{s} / 100 \mathrm{~mL}$ & 0,56 & 0,70 & 2,96 & 56,6 & 0,38 & 1,30 & 4,80 & 168 \\
Índice de TEA, $\mathrm{mJ} / \mathrm{g}$ & 341 & 967 & 1709 & 3088 & 526 & 1211 & 2083 & 3324 \\
Alongamento, $\%$ & 2,30 & 3,52 & 4,27 & 5,23 & 2,65 & 3,46 & 4,37 & 5,29 \\
Índice de tração, $\mathrm{Nm} / \mathrm{g}$ & 19,8 & 37,4 & 55,6 & 82,7 & 26,3 & 47,8 & 67,4 & 90,9 \\
Índice de rasgo, $\mathrm{mNm}{ }^{2} / \mathrm{g}$ & 3,51 & 6,27 & 9,36 & 10,6 & 4,82 & 5,46 & 9,02 & 10,5 \\
Índice de estouro, $\mathrm{kPam}{ }^{2} / \mathrm{g}$ & 1,07 & 2,23 & 3,61 & 6,03 & 1,59 & 2,98 & 4,74 & 6,89 \\
Comp. auto-ruptura, $\mathrm{km}$ & 2,18 & 4,12 & 6,11 & 9,15 & 2,89 & 5,29 & 7,42 & 10,0 \\
\hline
\end{tabular}

durante a polpação (JIANG et al., 2000), menores teores de ácidos hexenurônicos são mais desejáveis, uma vez que esses constituintes prejudicam o processo de branqueamento (GOMIDE et al., 2005) e a qualidade da polpa final (JANG etal., 2000; SIXTA; RUTKOWSKA, 2007). O mais baixo conteúdo de ácidos hexenurônicos na polpa PII pode indicar melhor resposta ao branqueamento para polpa com melhor qualidade de polpa branqueada.

O índice k/kappa corrigido foi obtido a partir da razão entre o valor do índice de absorção de luz (k) pelo valor do número kappa corrigido, de modo que a contribuição do número kappa devido aos ácidos hexenurônicos foi desconsiderada. O índice k é o coeficiente de absorção de luz da teoria proposta por Kubelka-Munk (ABNT, 2009). Segundo Li e Gellerstedt (1997), pode-se considerar a contribuição de uma unidade no número kappa a cada a 11,6 $\mu$ mol de ácidos hexenurônicos presentes na polpa. Ao descontar a contribuição dos ácidos hexenurônicos no número kappa e após obter a razão entre o índice de absorção de luz e o número kappa corrigido, tem-se o valor estimado do índice k/kappa corrigido, de modo que, para uma mesma madeira, valores menores desse índice são mais desejáveis, uma vez que indicam menor consumo de reagentes químicos de branqueamento e, com isso, melhores branqueabilidades (AL-DAJANI, 2001). A polpa PII apresentou índice $\mathrm{k} / \mathrm{kappa}$ corrigido inferior ao da polpa PI, o que sugere melhor branqueabilidade associada a essa polpa. Tal afirmação é coerente com o que afirmaram Ventorim et al. (2009), segundo os quais melhores branqueabilidades são verificadas nas polpas produzidas com menor temperatura de cozimento, para número kappa semelhante.

Tanto o conteúdo de ácidos hexenurônicos quanto o índice k/kappa corrigido apresentaram diferença significativa entre as polpas PI e PII e os resultados sugerem melhor resposta ao branqueamento com qualidade de polpa superior para a polpa produzida pela condição PII. Além disso, essa polpa apresentou 
ainda viscosidade intrínseca significativamente maior, o que, além de reforçar a afirmação anterior, indica que a condição de polpação PII foi mais adequada à polpação, com valores similares de número kappa, rendimento depurado e alvura. Com base nesses resultados, concluiu-se que alterações nas condições de cozimento aplicadas afetaram de modo mais intenso a integridade das fibras do que a composição química da polpa. Desse modo, mais baixa temperatura de cozimento, maior sulfidez e mais equilibrada distribuição da carga alcalina durante a polpação favoreceram a qualidade da polpa de eucalipto, para um mesmo valor de número kappa, rendimento depurado e alvura.

\subsection{Polpas branqueadas}

As polpas apresentaram alvuras similares após o branqueamento. A viscosidade intrínseca das polpas apresentou a maior diferença entre os parâmetros avaliados. A polpa produzida pela condição PII apresentou viscosidade intrínseca superior à polpa produzida pela condição PI. Esse resultado ampliou a diferença discreta, embora significativa, verificada para viscosidade intrínseca da polpa marrom, reafirmando o argumento de que a condição de polpação PII foi mais adequada para a polpação Kraft com maior proteção da integridade dos polissacarídeos da polpa.

A branqueabilidade foi avaliada mediante o consumo de químicos (base OXE) (GRUNDELIUS, 1993), para atingir a alvura de 89\% ISO. A interpolação foi necessária para possibilitar comparações entre os resultados. Como a branqueabilidade foi obtida pela razão entre o consumo de químicos pelo número kappa da polpa marrom, quanto menor o índice obtido, melhor a branqueabilidade da polpa. O menor índice (melhor branqueabilidade) foi apresentado pela polpa produzida pela condição PII, o que está de acordo com Ventorim et al. (2009), que afirmaram que as melhores branqueabilidades estão relacionadas com as polpas produzidas com menores temperaturas de cozimento, para um mesmo número kappa. Correlacionando os resultados do índice k/kappa corrigido (parâmetro da polpação) com os resultados de branqueabilidade (parâmetro do branqueamento) das polpas, percebeu-se que, quanto menor o índice $\mathrm{k} /$ kappa corrigido, melhor a branqueabilidade apresentada para a mesma polpa, indicando a existência de correlação válida entre índice $\mathrm{k} /$ kappa corrigido e branqueabilidade da polpa.

Revista Árvore, Viçosa-MG, v.39, n.3, p.575-584, 2015

\subsection{Refino e propriedades físico-mecânicas}

As polpas branqueadas foram refinadas a 0,750 , 1.500 e 3.000 níveis de revoluções. Os gráficos foram feitos, para cada polpa, correlacionando seus parâmetros de qualidade com o índice de tração. A escolha desse índice para as correlações gráficas ocorreu porque esse é um parâmetro usualmente utilizado em estudos de avaliação de propriedades físico-mecânicas, como o parâmetro de referência (QUEIROZ et al., 2004), e representa a propriedade mais exigida por diversas empresas para a produção de vários tipos de papéis (LONGUE JUNIOR, 2007). Verificou-se correlação positiva entre o nível de refino e o índice de tração e, para um mesmo nível de refino, as polpas produzidas pela condição PII alcançaram maiores valores do índice de tração (Figura 1). Do mesmo modo, para alcançar um mesmo índice de tração das polpas, foi necessário menor nível de refino para a polpa PII. Tais resultados indicaram que essa condição de polpação comprometeu menos a integridade físico-mecânica das fibras quando comparada com a condição PI, provavelmente devido à melhor e mais adequada distribuição da carga alcalina. Além disso, os resultados indicaram que a utilização da temperatura mais branda foi favorável à produção de polpa, promovendo menor ataque às fibras (menor perda de viscosidade intrínseca) sem comprometer seu rendimento e deslignificação. Analisando os índices de tração das polpas sem refino (nível 0 de refino), verificou-se maior índice de tração para a polpa PII, o que foi uma evidência de que, mesmo sem qualquer tratamento, as fibras geradas a partir dessa condição de polpação apresentaram maior resistência intrínseca

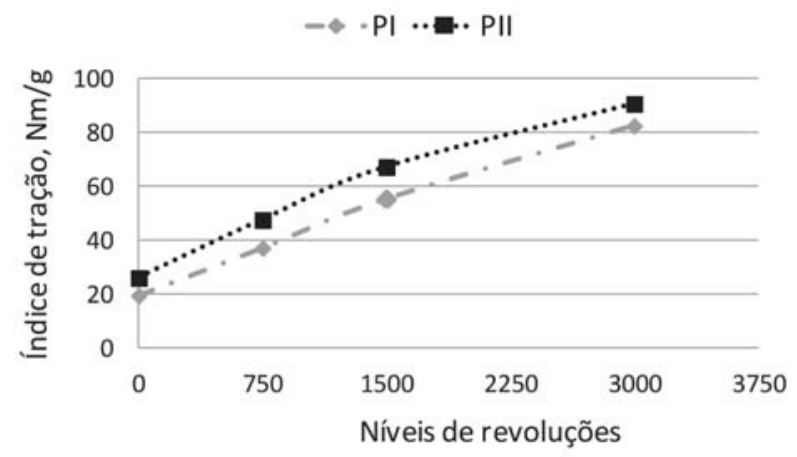

Figura 1 - Efeito da condição de polpação no índice de tração das polpas refinadas.

Figure 1 - Effect of pulping condition on the refined pulp tensile index. 
devido ao fato de terem sido menos atacadas durante as etapas de polpação e branqueamento.

Com o intuito de facilitar a visualização do comportamento dos testes físico-mecânicos em função do nível de refino e do tipo de polpa (PI e PII), foram feitos gráficos relacionando cada uma das propriedades físico-mecânicas com o índice de tração, a propriedade mais exigidas por diversas empresas para a produção de vários tipos de papéis (LONGUE JUNIOR, 2007). O índice de tração apresentou correlação positiva com o nível de refino e, em cada curva, os pontos destacados correspondem a 0, 750, 1.500, 3.000 níveis de revoluções, respectivamente.

A drenabilidade da polpa, que é determinada a partir do grau Schopper Riegler, correlacionou-se, de forma positiva, com o índice de tração para ambas as condições de polpação (Figura 2A). Verificou-se que a condição de polpação PII atingiu valores ligeiramente superiores para a drenabilidade com o mesmo nível de refino aplicado, em comparação com a condição PI. A variação da drenabilidade das polpas para um mesmo índice de tração foi muito pequena, apesar da polpa PI ter apresentado maiores índices de tração entre 30 e 80 Nm/g.

A densidade aparente apresentou correlação positiva com o índice de tração, e a polpa produzida pela condição de polpação PI apresentou tendência de maior densidade aparente para um mesmo índice de tração (Figura 2B). Comparando as densidades aparentes das polpas com o nível de refino aplicado, somente no nível de refino mais baixo (nível 0) a diferença entre as polpas foi pronunciada.

O parâmetro de resistência ao ar, quando correlacionado com o índice de tração, apresentou comportamento semelhante para as duas polpas até o índice de tração, em torno de $50 \mathrm{Nm} / \mathrm{g}$. A partir desse ponto foi verificado um aumento considerável nos valores de resistência ao ar, com comportamento distinto entre as polpas. Verificou-se que apenas para refinos realizados a 1.500 e 3.000 níveis de revoluções os valores de resistência ao ar foram distintos entre as polpas, com correlação positiva entre índice de tração e grau de refino (Figura 2C).

O índice TEA pouco variou entre as polpas, apresentando, no entanto, tendência de maiores índices para a polpa produzida pela condição PI, considerando um mesmo índice de tração (Figura 2D). Índice TEA e índice de tração apresentaram sempre correlação positiva. Comparando os níveis de revoluções, a polpa produzida pela condição PII atingiu maiores índices TEA que a polpa produzida pela condição PI, quando refinada a um mesmo nível de refino.

O parâmetro de alongamento apresentou maiores valores para as polpas produzidas pela condição de polpação PI, em comparação com um mesmo índice de tração, e apresentou comportamento semelhante nas curvas das duas condições, com correlação positiva entre os parâmetros (Figura 2E). Em um mesmo nível de refino, as polpas apresentaram valores semelhantes de alongamento, ressaltando-se, entretanto, que nessas condições o incremento no índice de tração foi maior na polpa PII. A polpa PI, quando não refinada (nível 0 de refino), apresentou menor resultado de alongamento que a polpa PII, o que se correlaciona com as características intrínsecas das fibras dessa polpa.

O índice de rasgo apresentou correlação positiva com o índice de tração (Figura 2F). Para o mesmo índice de tração, a polpa PI apresentou maior índice de rasgo que a polpa PII. Os índices de rasgo apresentados pelas polpas nos demais níveis de revoluções foram semelhantes, à exceção das polpas não refinadas (nível 0 de refino). A polpa PII, quando não refinada (nível 0 de refino), apresentou maior índice de rasgo que a polpa PI. O comportamento das curvas que descrevem o índice de rasgo em razão do índice de tração apresentaram trajetórias distintas.

As curvas referentes ao índice de estouro e comprimento de auto-ruptura apresentaram trajetórias semelhantes em ambas as polpas. Houve, ainda, sobreposição das curvas das polpas para o índice de tração, tanto quando este foi correlacionado com o índice de estouro quanto quando foi correlacionado com o comprimento de auto-ruptura. Para um mesmo índice de tração, os valores de índice de estouro e comprimento de auto-ruptura foram semelhantes entre as polpas (Figuras $2 \mathrm{G}$ e $2 \mathrm{H}$, respectivamente). Em um mesmo nível de refino, a polpa produzida pela condição PII apresentou valores mais elevados de índice de estouro e comprimento de autorruptura.

\section{CONCLUSÕES}

Verificou-se que as diferentes condições de temperatura, tempo, carga alcalina e sulfidez utilizados na polpação influenciaram as propriedades físico-

Revista Árvore, Viçosa-MG, v.39, n.3, p.575-584, 2015 

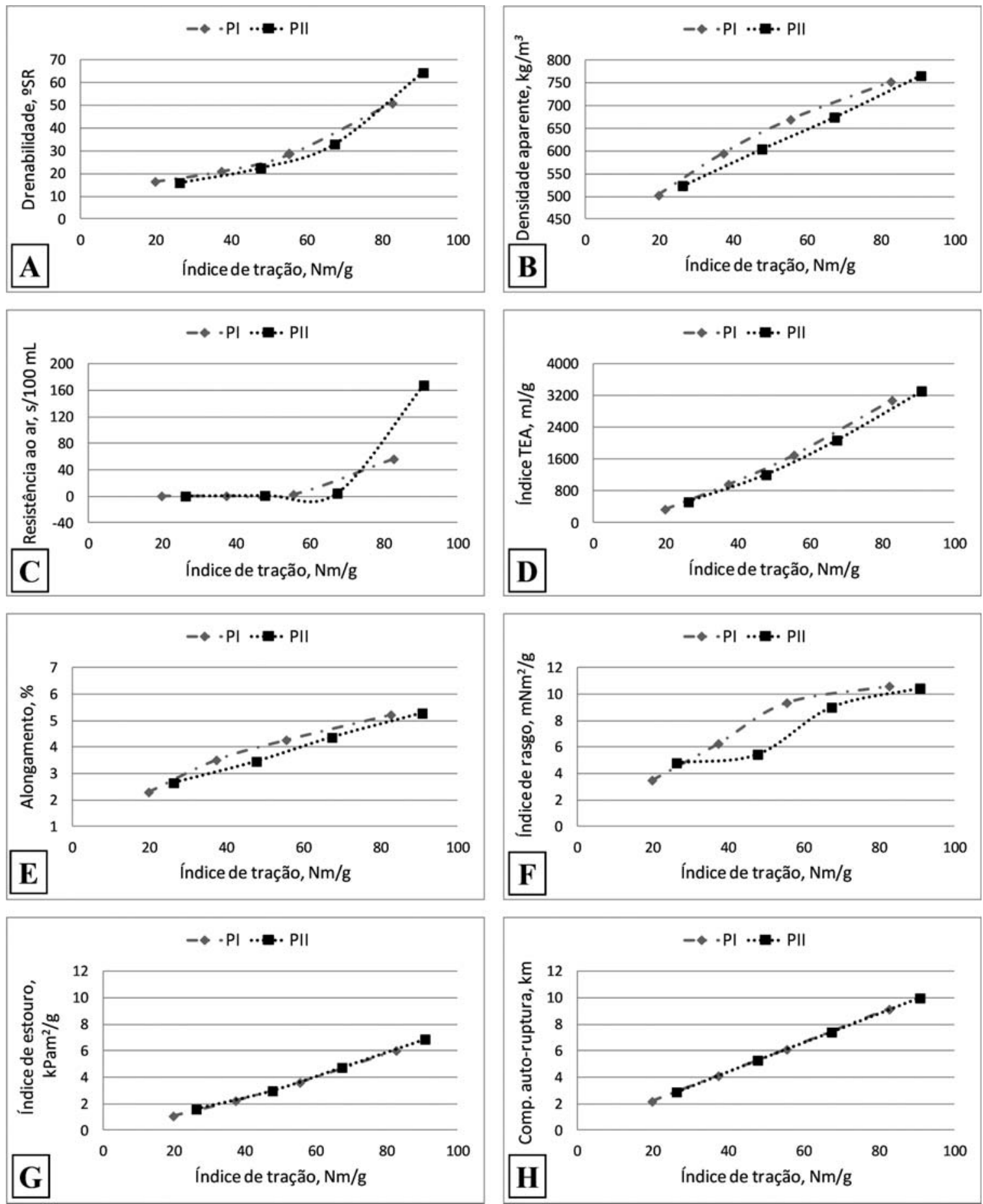

Figura 2 - Efeito da condição de polpação na drenabilidade (A), densidade aparente (B), resistência ao ar (C), índice TEA (D), alongamento (E), índice de rasgo (F), índice de estouro (G) e comprimento de auto-ruptura (H), em função do índice de tração das polpas refinadas.

Figure 2 - Effect of pulping condition on the drainability (A), apparent density (B), air resistance (C), TEA index (D), stretching $(E)$, tear index $(F)$, burst index $(G)$, and self-breaking length $(H)$, in funtion of the refined pulp tensile index.

Revista Árvore, Viçosa-MG, v.39, n.3, p.575-584, 2015 
mecânicas do papel. As condições de polpação promoveram diferentes viscosidades intrínsecas, conteúdos de ácidos hexenurônicos e índices k/kappa corrigidos, para um mesmo valor de número kappa, rendimento depurado e alvura das polpas marrons. As condições de polpação influenciaram ainda as viscosidades intrínsecas e a branqueabilidades das polpas branqueadas para uma mesma alvura.

Para um mesmo índice de tração, a polpa PI apresentou maiores valores dos parâmetros de drenabilidade, densidade aparente, índice TEA, alongamento e índice de rasgo. Para os demais parâmetros avaliados, os resultados entre polpas foram similares. A polpa PII, entretanto, atingiu o mesmo índice de tração da polpa PI, necessitando de menor nível de refino e, consequentemente, menor gasto de energia. Além disso, a maior resistência da polpa PI quando avaliada em termos de índice de tração se deve muito mais aos efeitos do refino, que para ela foram mais intensos (maior nível de refino) que a resistência intrínseca das fibras, como verificado na polpa PII, que quase sempre apresentou maiores resultados dos parâmetros avaliados, mesmo sem refino (nível 0 de refino).

Para um mesmo nível de refino, a polpa PII apresentou os maiores valores de índice de tração, drenabilidade, índice TEA, índice de estouro e comprimento de autoruptura. Densidade aparente, índice de rasgo e alongamento apresentaram resultados similares entre polpas.

Por fim, conclui-se que a melhor condição de polpação para o desenvolvimento das propriedades físico-mecânicas das polpas foi a PII, uma vez que, ao preservar mais a qualidade da polpa durante a polpação e o branqueamento, apresentou maiores índices para as propriedades físicomecânicas, mesmo sem refino (nível 0 de refino). A polpa PII atingiu ainda um mesmo índice de tração (parâmetro de qualidade observado para o papel), com menor nível de refino (parâmetro controlável no processo).

\section{AGRADECIMENTOS}

À Fibria - Unidade Jacareí, pelo espaço físico e suporte técnico fornecidos durante o desenvolvimento deste estudo.

\section{REFERÊNCIAS}

AL-DAJANI, W.W. On the bleachability of alkaline pulps. The influence of residual lignin structure. 2001. 78f. Thesis
(Doctoral Dissertation) - Royal Institute of Technology (KTH) Departament of Pulp and Paper Chemistry and Technology, Stockholm, 2001.

\section{ASSOCIAÇÃO BRASILEIRA DE NORMAS} TÉCNICAS - ABNT. NBR ISO 9416: Pastas celulósicas e papel - Determinação dos coeficientes de espalhamento e absorção de luz (usando a teoria de Kubelka-Munk). Rio de Janeiro: 2009.

CARVALHO, D.M.; SILVA, M.R.; COLODETTE, J.L. Efeito da qualidade da madeira no desempenho da polpação kraft. Ciência Florestal, v. 24, n. 3, p. 677-684, 2014.

CARVALHO, D.M.; SILVA, M.R.; COLODETTE, J.L. Estudo da branqueabilidade da polpa kraft de eucalipto. Ciência Florestal, v. 25, n. 1, p. 185-197, 2015.

DANIEL, A. I. D.; PASCOAL NETO, C.; EVTUGUIN, D.V.; SILVESTRE, A.J.D. Hexenuronic acid contents of Eucalyptus globulus kraft pulps: variation with pulping condition and effect on ECF bleachability. Tappi Journal, v.2, n.5, p.3-8, 2003.

GOMIDE, J.L.; COLODETTE, J.L; OLIVEIRA, R.C.; SILVA, C.M. Caracterização tecnológica para produção de celulose, da nova geração de clones de Eucalyptus do Brasil. Revista Árvore, v.29, n.1, p.129-137, 2005.

GRUNDELIUS, N.R. Oxidation equivalents, OXE an alternative to active chlorine. Tappi

Journal, v. 76, n.1, p.133-135, 1993.

GUSTAVSSON, C.; SJÖSTRÖM, K.; AL-DAJANI, W.W. The influence of cooking conditions on the bleachability and chemical structure of kraft pulps. Nordic Pulp and Paper Research Journal, v.14, n.1, p.71-81, 1999.

JIANG, Z., van LIEROP, B. V., BERRY, R. Hexenuronic acid groups in pulping and bleaching chemistry. Tappi Journal, v.83, n.1, p.167-175, 2000.

LI, J.; GELLERSTEDT, G. The contribution to kappa number from hexenuronic acid groups in pulp xylan. Carbohydrate Research, v.302, n.3-4, p.213-218, 1997.

Revista Árvore, Viçosa-MG, v.39, n.3, p.575-584, 2015 
LONGUE JUNIOR, D. Métodos alternativos para aproveitamentos das

hemiceluloses da madeira de eucalipto na indústria de celulose Kraft. 2007. $117 \mathrm{f}$. Dissertação (Mestrado em Ciência Florestal) Universidade Federal de Viçosa, Viçosa, MG, 2007.

MANFREDI, M.; OLIVEIRA, R.C.; SILVA, J.C. Melhoramento das propriedades de papéis reciclados através da ultrassonificação das fibras e adição de xilanas. Revista Árvore, v.36, n.4, p.777-785, 2012.

OLIVEIRA, J.G.L.; OLIVEIRA, J.T.S.; ABAD, J.I.M.; SILVA, A.G.; FIEDLER, N.C.; VIDAURE, G.B. Parâmetros quantitativos da anatomia da madeira de eucalipto que cresceu em diferentes locais. Revista Árvore, v.36, n.3, p.559-567, 2012.

QUEIROZ, S.C.S.; GOMIDE, J.L.; COLODETTE, J.L.; OLIVEIRA, R.C. Influência da densidade básica da madeira na qualidade da polpa kraft de clones híbridos de Eucalyptus grandis W. Hill ex Maiden X Eucalyptus urophylla S. T. Blake. Revista Árvore, v.28, n.6, p.901-909, 2004.
SCANDINAVIAN PULP, PAPER AND BOARD TEST METHODS - SCAN. SCAN:CM 40:94 - Size distribution. Stockholm: 2004.

SILVA, D.J.; GOMIDE, J.L.; COLODETTE, J.L. Utilização de surfactantes, na produção kraft de madeira de eucalipto, como auxiliar na remoção de extrativos lipofílicos. Revista Árvore, v.28, n.6, p.911-917, 2004.

SIXTA, H.; RUTKOWSKA, E.W. Estudo cinético abrangente da polpa kraft de Eucalyptus globulus. O Papel, v.68, n.2, p.68-81, 2007.

TECHNICALASSOCIATION OF THE PULP AND PAPER INDUSTRY - TAPPI. Tappi Standard Methods. Atlanta: TAPPI, 2011.

VENTORIM, G.; CARASCHI, J.C.; COLODETTE, J.L.; GOMIDE, J.L. A influência dos ácidos hexenurônicos no rendimento e na branqueabilidade da polpa kraft. Química Nova, v.32, n.2, p.373-377, 2009.

ZANUNCIO, A.J.V.; COLODETTE, J.L. Teores de lignina e ácidos urônicos na madeira e polpa celulósica de eucalipto. Revista Árvore, v.35, n.2, p.341-347, 2011. 